\title{
Protective effects of recombinant human brain natriuretic peptide in perioperative period during open heart surgery
}

\author{
YUNBIN XU, YONG LI, WEIGUO BAO and SHI QIU
}

Department of Cardiovascular Surgery, The Second Hospital of Shandong University, Jinan, Shandong 250033, P.R. China

Received April 10, 2017; Accepted August 22, 2017

DOI: $10.3892 /$ etm.2018.5750

\begin{abstract}
The aim of the present study was to evaluate the protective effects and safety aspects of recombinant human brain natriuretic peptide (rhBNP) on cardiac functions of patients undergoing open-heart surgery during perioperative period. In total, 150 patients undergoing open heart surgery in the Second Hospital of Shandong Universty from August 2015 to July 2016 were randomly divided into control group and observation group each with 75 cases. Patients in control group were treated by routine rehabilitation while patients in the observation group were treated by both the routine rehabilitation and rhBNP. All the observations were made before operation, after operation and 7 days after operation. The changes of N-terminal pro-brain natriuretic peptide (NT-proBNP) of patients, the left ventricular ejection fraction (LVEF), cardiac function [Cardiac output (CO), pulmonary capillary wedge pressure (PAWP) and central venous pressure (CVP)] of patients were measured. Further, respirator support time, ICU stay time, incidence of complications and vital signs (BP, $\mathrm{HR}, \mathrm{SaO} 2)$ of patients in the two groups were also compared. NT-proBNP levels of all patients improved after operation but it decreased in both groups after 7 days of operation. The decrease of NT-proBNP levels in observation group was significantly higher than that of control group. Whereas, LVEF, CO, PAWP and CVP of patients in both the groups increased after operation but effects were significantly higher in the observation group after 7 days of medication. Respirator support time and ICU stay time of patients in observation group were significantly shorter than those in control group, and the incidence of postoperative complications of patients in the observation group were significantly lower than the control group. Moreover, BP, HR and $\mathrm{SaO} 2$ of patients in observation group were significantly elevated in
\end{abstract}

Correspondence to: Dr Yunbin Xu, Department of Cardiovascular Surgery, The Second Hospital of Shandong University, 247 Beiyuan Road, Tianqiao, Jinan, Shandong 250033, P.R. China

E-mail: c8499931dileixu@163.com

Key words: recombinant human brain natriuretic peptide, open heart surgery, perioperative period, cardiac function comparison to control group $(\mathrm{P}<0.05)$. Recombinant human brain natriuretic peptide (rhBNP) could significantly improve the cardiac functions of patients after open heart surgery, and is safe as well as reliable.

\section{Introduction}

The rapid development of economy and the improvement of people's living standards allow more patients to accept heart surgery for the improvement of quality of life including the heart valve repair or replacement, cardiac surgery and coronary artery bypass grafting (1). The preoperative cardiac reserve functions of patients before the heart surgery are usually poor. Further, the surgical trauma, intraoperative myocardial ischemia and CPB are also prone to myocardial ischemia as well as ischemia reperfusion injury leading to low cardiac output syndrome $(2,3)$. Therefore, it is very important to strengthen the protection of cardiac functions and prevention of the myocardial damage in patients undergoing cardiac surgery. This process would play an important role in improving the success rates of surgery and prognosis (4). Brain natriuretic peptide is a member of natriuretic peptide family. Recombinant human brain natriuretic peptide (rhBNP) is a kind of medicine for the treatment of heart failure, and is a recommended drug for acute as well as chronic heart failure (5). The related research showed that rhBNP has the ability to maintain the normal cardiac output, dilation of the pulmonary circulation/coronary circulation, reduction in cardiac load, protection of ischemic myocardium (5). Moreover, it could also achieve good clinical effects on heart functions after cardiac surgery (5). In the present study, patients were treated with the combination of routine treatment with recombinant human brain natriuretic peptide (rhBNP) after open-heart surgery and the clinical potential of this combination was evaluated.

\section{Patients and methods}

General information. One hundred and fifty patients undergoing open heart surgery in the Second Hospital of Shandong Universty from August 2015 to July 2016 were randomly divided into control group and observation group by computer, with 75 cases in each group. Patients in control group were treated by routine rehabilitation; patients in the observation group were treated by routine rehabilitation and rhBNP. Inclusion criteria: i) heart function grade II-III of 
Table I. Baseline data of two groups.

\begin{tabular}{lcccr}
\hline Item & $\begin{array}{c}\text { Observation group } \\
\mathrm{n}=75\end{array}$ & $\begin{array}{c}\text { Control group } \\
\mathrm{n}=75\end{array}$ & $\mathrm{t} / \chi^{2}$ & P-value \\
\hline Age (years) & $30-68$ & $30-65$ & & \\
Sex (male/female) & $39 / 36$ & $34 / 41$ & 0.053 & 0.513 \\
Average age (years) & $43.56 \pm 6.42$ & $43.85 \pm 6.53$ & 0.274 & 0.784 \\
BMI $\left(\mathrm{kg} / \mathrm{m}^{2}\right)$ & $22.13 \pm 3.45$ & $22.76 \pm 3.38$ & 1.130 & 0.261 \\
Operation type (n, \%) & & & 0.042 & 0.874 \\
$\quad$ Valve repair or replacement & $29(38.67)$ & $31(41.33)$ & & \\
$\quad$ Correction of congenital heart disease & $19(25.33)$ & $20(26.67)$ & & \\
$\quad$ Coronary artery and major blood vessel related surgery & $27(36.00)$ & $24(32.00)$ & & 0.739 \\
Preoperative cardiac function (NYHA) & & & 0.027 & \\
$\quad$ Grade II (n, \%) & $32(42.67)$ & $29(38.67)$ & & \\
Grade III (n, \%) & $43(57.33)$ & $46(61.33)$ & & \\
\hline
\end{tabular}

Table II. Comparison of NT-proBNP levels in two groups.

\begin{tabular}{lcccccc}
\hline Group & No. of cases & Before operation & $\begin{array}{c}\text { Before medication } \\
\text { after operation }\end{array}$ & $\begin{array}{c}\text { Seven days } \\
\text { after medication }\end{array}$ & F-value & P-value \\
\hline Observation group & 75 & $1315.35 \pm 221.14$ & $1934.06 \pm 321.13$ & $472.23 \pm 51.02$ & 76.312 & $<0.001$ \\
Control group & 75 & $1326.06 \pm 231.23$ & $1963.73 \pm 335.25$ & $1062.76 \pm 311.17$ & 75.431 & $<0.001$ \\
t-value & 0.290 & 0.129 & 16.219 & & \\
P-value & 0.772 & 0.897 & $<0.001$ & & \\
\hline
\end{tabular}

American New York Heart Association; ii) cardiopulmonary bypass support for cardiac surgery includes: valve repair or replacement, correction of congenital heart disease, coronary artery and major blood vessel related surgery; and iii) signed informed consent. Exclusion criteria: i) patients with cardiac shock and hypotension (SBP $<90 \mathrm{mmHg}$ ); ii) severe renal insufficiency; and iii) allergy to the study drug and lactating women. There was no significant difference between the two groups of patients in general information $(\mathrm{P}>0.05)$, comparability is shown in Table I. The study was approved by the Ethics Committee of the Second Hospital of Shandong Universty and informed consents were signed by the patients and/or guardians.

Surgical methods. All patients underwent cardiac surgery with cardiopulmonary bypass support including: valve repair or replacement, repair of congenital heart disease, coronary artery and major blood vessel related surgery. Postoperative patients with tracheal intubation were sent to ICU to monitor the treatment along with maintenance of circulation and smooth respiration. Further, the late extubation extra corporeal circulation machine (German Stockert-sc type) and membrane oxygen device were used in the two groups of patients for the purpose of cardiopulmonary bypass. Compounds sodium chloride $(900 \mathrm{ml})$, dexamethasone $(10 \mathrm{mg})$, mannitol $(250 \mathrm{ml})$ were used as the pre flushing fluids. Natriuretic peptide (Chengdu Nuodikang Biological Pharmaceutical Co. Ltd.: license number: NMPN S20050033) was added in observation group. Usage and dosage: Patients began to use the above dose regime within $24 \mathrm{~h}$ after surgery with continuous use of $24-48 \mathrm{~h}$. The recommended medication time was more than $48 \mathrm{~h}$.

Evaluation criterion. Venous blood $4 \mathrm{ml}$ of patients was collected before operation, after operation and 7 days after the operation. The $\mathrm{N}$-terminal pro-brain natriuretic peptide (NT-proBNP) of patients were detected by automatic chemiluminescence immunoassay. The left ventricular ejection fraction (LVEF) was measured by color Doppler echocardiography before operation, after operation and 7 days after the operation. Cardiac function [cardiac output (CO), pulmonary capillary wedge pressure (PAWP), central venous pressure (CVP)] of patients were recorded and observed before the operation, after the operation and 7 days after the operation. The ventilator support time and ICU retention time of two groups of patients were recorded. The incidence rate of postoperative complications was observed. Blood pressure (BP), heart rate (HR) and blood oxygen saturation ( $\mathrm{SaO} 2)$ were monitored and observed after 7 days of treatment.

Statistical analysis. SPSS 19.0 (SPSS Inc., Chicago, IL, USA) software was used for data processing. Measurement data are expressed by mean $\pm \mathrm{SD}$, with t-test; count data were expressed by ratio with $\chi^{2}$ test, and $\mathrm{P}<0.05$ was considered to indicate a statistically significant difference. 
Table III. Comparison of changes of LVEF in two groups.

\begin{tabular}{lcccccr}
\hline Group & No. of cases & Before operation & $\begin{array}{c}\text { Before medication } \\
\text { after operation }\end{array}$ & $\begin{array}{c}\text { Seven days } \\
\text { after medication }\end{array}$ & F-value & P-value \\
\hline Observation group & 75 & $43.35 \pm 3.14$ & $50.06 \pm 3.13$ & $56.23 \pm 3.02$ & 9.432 & $<0.001$ \\
Control group & 75 & $43.06 \pm 3.23$ & $49.73 \pm 3.25$ & $51.76 \pm 3.17$ & 7.581 & $<0.001$ \\
t-value & 0.558 & 0.633 & 8.842 & & \\
P-value & 0.578 & 0.527 & $<0.001$ & & \\
\hline
\end{tabular}

\section{Results}

T-proBNP levels of all patients improved after operation. NT-proBNP levels of patients in both groups decreased 7 days after operation, and the decrease of NT-proBNP level in observation group was significantly higher than control group $(\mathrm{P}<0.05)$ (Table II).

The LVEF of patients in the groups increased after operation. LVEF of patients in observation group was significantly higher than that in control group after 7 days of medication $(\mathrm{P}<0.05)$. (Table III).

Comparison of the heart function indexes of two groups. The indexes of CO, PAWP and CVP were significantly improved in the two groups compared with before operation, and the improvement degree of the observation group was better than that of the control group 7 days after medication $(\mathrm{P}<0.05)$ (Figs. 1-3).

Mechanical ventilation time, ICU indwelling time and postoperative complications of two groups of patients. Compared with the control group, mechanical ventilation time and ICU indwelling time in the observation group were significantly shorter than those in the control group. Further, the incidence of postoperative complications was significantly lower than that of the control group, and the differences were statistically significant (Table IV).

Comparison of vital signs in two groups of patients during perioperative period. $\mathrm{SBP}, \mathrm{DBP}, \mathrm{HR}$, and $\mathrm{SaO} 2$ indexes of the observation group were significantly better than those of the control group $(\mathrm{P}<0.05)$ (Table $\mathrm{V})$.

\section{Discussion}

Cardiac reserve function is often affected after heart surgery due to surgical trauma and myocardial ischemia. Moreover, these patients are prone to myocardial ischemia and ischemia reperfusion injury that in turn leads to a variety of complications like heart failure, endotoxemia, the systemic inflammatory response syndrome and low cardiac output syndromes $(6,7)$. The low cardiac output syndrome is the most severe complication with high mortality, and there are many factors of incidence, such as poor preoperative cardiac function in patients, myocardial ischemia time, poor cardiac malformation correction, intracardiac operation time, aortic clamping time, postoperative blood volume insufficiency, arrhythmia,

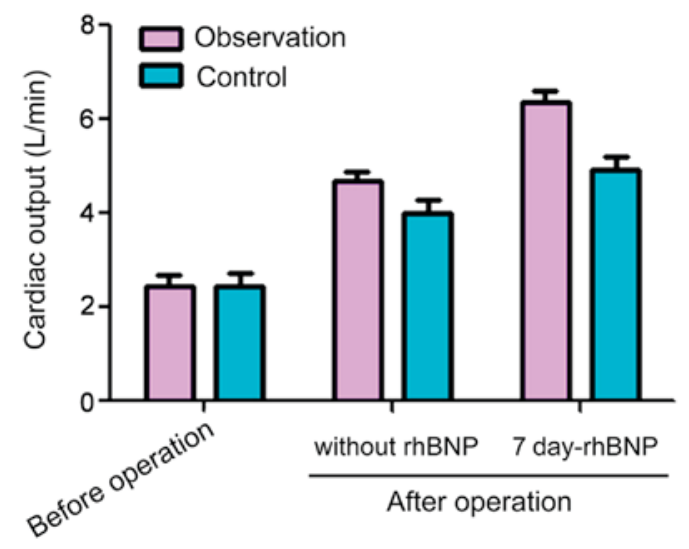

Figure 1. Cardiac output of two groups at different time points.

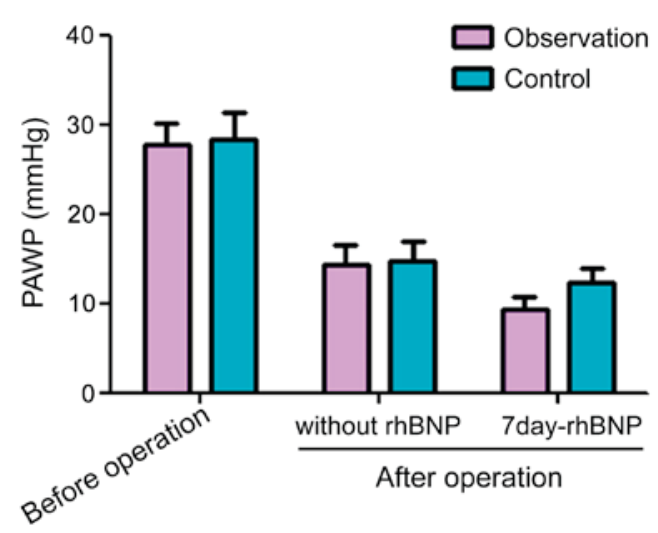

Figure 2. Pulmonary capillary wedge pressure (PAWP) of two groups at different time points.



Figure 3. Central venous pressure (CVP) of two groups at different time points. 
Table IV. Comparison of ventilator support and ICU indwelling time and postoperative complications of two groups of patients.

\begin{tabular}{lcccc}
\hline Group & No. of cases & $\begin{array}{c}\text { Ventilator support } \\
\text { time }(\mathrm{h})\end{array}$ & $\begin{array}{c}\text { ICU indwelling } \\
\text { time (h) }\end{array}$ & $\begin{array}{c}\text { Postoperative } \\
\text { complication }(\mathrm{n}, \%)\end{array}$ \\
\hline Observation group & 75 & $12.15 \pm 1.34$ & $26.16 \pm 3.33$ & $4(5.33)$ \\
Control group & 75 & $16.76 \pm 1.53$ & $36.83 \pm 3.45$ & $13(17.33)$ \\
t-value & 19.630 & 19.271 & 4.247 & 0.039 \\
P-value & $<0.001$ & $<0.001$ & & \\
\hline
\end{tabular}

Table V. Comparison of vital signs in two groups of patients during perioperative period.

\begin{tabular}{lccccc}
\hline Group & No. of cases & SBP $(\mathrm{mmHg})$ & DBP $(\mathrm{mmHg})$ & HR (beats/min) & SaO2 (\%) \\
\hline Observation group & 75 & $115.35 \pm 3.14$ & $64.06 \pm 3.13$ & $90.06 \pm 8.17$ & $98.23 \pm 1.02$ \\
Control group & 75 & $108.06 \pm 3.23$ & $59.73 \pm 3.25$ & $95.62 \pm 9.29$ & $94.76 \pm 1.17$ \\
t-value & & 14.015 & 8.311 & 3.899 & 19.360 \\
P-value & $<0.001$ & $<0.001$ & 0.0001 & $<0.001$ \\
\hline
\end{tabular}

cardiac tamponade and pulmonary artery hypertension (8). The reduction of the myocardial damage post-cardiac surgery and the protection of heart function have become the focus of clinical attention. Moreover, they have a profound impact on the success rate of surgery and prognosis of patients (9).

The secretion of NT-proBNP in patients with heart disease is closely related to the ventricular pressure load and volume load. When the ventricular wall tension load in patients increases, the NT-proBNP level would rise sharply. Moreover, the monitoring of it could prevent postoperative complications $(10,11)$. Moreover, the plasma NT-proBNP levels of patients would continue to rise after open-heart surgery (12). The results of the present study showed that the NT-proBNP of patients of both groups increased after operation, which might be affected by anesthesia, surgical trauma, hemodynamic abnormalities, inflammatory stimulation, CPB, myocardial damage and decreased contractile ability. However, the levels of NT-proBNP in the two groups began to decrease after 7 days of treatment. This was the result after drug treatment that included inflammatory reaction of patients (13).

The postoperative CO, PAWP and CVP indicators of the two groups of patients were significantly improved and the observation group was significantly better than the control group after 7 days of treatment $(\mathrm{P}<0.05)$. The above observation could be justified in the light of the fact that the natriuretic peptide has balanced expansion arteriovenous/coronary artery diastolic function (14). A related study also showed improvements in the hemodynamic parameters after $15 \mathrm{~min}$ of treatment (15). The natriuretic peptide could improve the heart rate through the comprehensive effect (16). The results of this study showed that postoperative LVEF were higher than preoperative in the two groups of patients, and the observation group was significantly higher than the control group after 7 days of treatment $(\mathrm{P}<0.05)$. Moreover, natriuretic peptide has ability to directly affect myocardial cells, thereby reducing myocardial oxygen consumption, with inhibition of excessive stress reaction of the circulatory system, so as to have a protective effect on the heart $(17,18)$.

In the present study, SBP, DBP, $\mathrm{HR}$, and $\mathrm{SaO} 2$ indexes of the observation group were significantly better than those of the control group $(\mathrm{P}<0.05)$. This is due to the natriuretic peptide that has positive chronotropic effect, which not only caused reflex tachycardia, but also inhibited cardiac sympathetic nerve activity, thereby adjusted the blood pressure (19). Moreover, ICU indwelling time and ventilator support were also reduced via natriuretic peptide treatment. In summary, recombinant human brain natriuretic peptide (rhBNP) could protect the cardiac functions of patients after open-heart surgery, and it is safe and reliable. However, for the concrete conclusions, the study needs further exploration in future as the sample size and time were limited in the present study.

\section{References}

1. Pontoni G,Ferrari S, Gabbieri D, Pedulli M, Gambetti D, Ghidoni I and Rigatelli M: FC28-04 - Quality of life assessment after cardiac surgery in octogenarians: Is it really feasible? Eur Psychiatry 26: 1974, 2011. http://www.em-consulte.com/article/289736/fc28-04quality-of-life-assessment-after-cardiac-s.

2. Massé L and Antonacci M: Low cardiac output syndrome: Identification and management. Crit Care Nurs Clin North Am 17: 375-383, 2005.

3. Algarni KD, Maganti M and Yau TM: Predictors of low cardiac output syndrome after isolated coronary artery bypass surgery: Trends over 20 years. Ann Thorac Surg 92: 1678-1684, 2011.

4. Mangano DT, Hollenberg M, Fegert G, Meyer ML, London MJ, Tubau JF and Krupski WC; The Study of Perioperative Ischemia (SPI) Research Group: Perioperative myocardial ischemia in patients undergoing noncardiac surgery - I: Incidence and severity during the 4 day perioperative period. J Am Coll Cardiol 17: 843-850, 1991.

5. He XM, Chen L, Luo JB, Feng XX, Zhang YB, Chen QJ, Ji XL and Wang TS: Effects of rhBNP after PCI on non-invasivehemodynamic in acute myocardial infarction patients with left heart failure. Asian Pac J Trop Med 9: 791-795, 2016.

6. Targońska S, Kozioł MM, Czajkowski M, Stążka J and KoziołMontewka M: Sternal wound complications after cardiac surgery - a case report. Wiad Lek 68: 95-98, 2015 (In Polish). 
7. Kerneis CK, Lafarge AL, Larnier LL, Scalbert F, Brusset AB, Estagnasie PE and Squara PS: Bowel and related complications after cardiac surgery. Crit Care 19 (Suppl 1): P375, 2015.

8. Howell NJ, Ashrafian H, Drury NE, Ranasinghe AM, Contractor H, Isackson H, Calvert M, Williams LK, Freemantle N, Quinn DW, et al: Glucose-insulin-potassium reduces the incidence of low cardiac output episodes after aortic valve replacement for aortic stenosis in patients with left ventricular hypertrophy: Results from the Hypertrophy, Insulin, Glucose, and Electrolytes (HINGE) trial. Circulation 123: 170-177, 2011.

9. Howard BT, Iles TL, Coles JA, Sigg DC and Iaizzo PA: Reversible and irreversible damage of the myocardium: Ischemia/reperfusion injury and cardioprotection. In: Handbook of Cardiac Anatomy, Physiology, and Devices. 3rd edition. Springer International Publishing, New York, 2015.

10. Madamanchi C, Alhosaini H, Sumida A and Runge MS: Obesity and natriuretic peptides, BNP and NT-proBNP: Mechanisms and diagnostic implications for heart failure. Int J Cardiol 176 611-617, 2014.

11. Oremus M, Don-Wauchope A, McKelvie R, Santaguida PL, Hill S, Balion C, Booth R, Brown JA, Ali U, Bustamam A, et al: BNP and NT-proBNP as prognostic markers in persons with chronic stable heart failure. Heart Fail Rev 19: 471-505, 2014.

12. Boer BP, Vieira ML, Sampaio RO, Abensur H, Oliveira AG, Fernandes JR and Grinberg M: Correlation to NT-ProBNP and remodeling after cardiac surgery. Arq Bras Cardiol 100: 469-475, 2013.

13. Recombinant Human Brain Natriuretic Peptide Multicenter Clinical Study Group; Hu DY: Efficacy and safety of intravenous recombinant human brain natriuretic peptide in patients with decompensated acute heart failure: A multicenter, randomized, open label, controlled study. Zhonghua Xin Xue Guan Bing Za Zhi 39: 305-308, 2011 (In Chinese).
14. Xing K, Fu X, Wang Y, Li W, Gu X, Hao G, Miao Q, Li S, Jiang Y, Fan W, et al: Effect of rhBNP on renal function in STEMI-HF patients with mild renal insufficiency undergoing primary PCI. Heart Vessels 31: 490-498, 2016.

15. Zhang S and Wang Z: Effect of recombinant human brain natriuretic peptide (rhBNP) versus nitroglycerin in patients with heart failure: A systematic review and meta-analysis. Medicine (Baltimore) 95: e4757, 2016.

16. Zhu XQ, Hong HS, Lin XH, Chen LL and Li YH: Changes in cardiac aldosterone and its synthase in rats with chronic heart failure: an intervention study of long-term treatment with recombinant human brain natriuretic peptide. Braz J Med Biol Res 47: 646-654, 2014

17. Zhang J, Zhang L, Wu Q, Liu H and Huang L: Recombinant human brain natriuretic peptide therapy combined with bone mesenchymal stem cell transplantation for treating heart failure in rats. Mol Med Rep 7: 628-632, 2013.

18. Bakkehaug JP, Kildal AB, Engstad ET, Boardman N, Næsheim T, Rønning L, Aasum E, Larsen TS, Myrmel T and How OJ: Response to letter regarding article, 'Myosin activator omecamtiv mecarbil increases myocardial oxygen consumption and impairs cardiac efficiency mediated by resting myosin ATPase activity'. Circ Heart Fail 8: 1142, 2015.

19. Lyu T, Zhao Y, Zhang T, Zhou W, Yang F, Ge H, Ding S, Pu J and He B: Natriuretic peptides as an adjunctive treatment for acute myocardial infarction: Insights from the meta-analysis of 1,389 patients from 20 trials. Int Heart J 55: 8-16, 2014. International (CC BY-NC-ND 4.0) License. 